Journal of Business and Tourism

\title{
Impact of work-family conflict on deviant workplace behavior through stress and burnout
}

\section{A sequential mediation model}

\author{
Dr. Shazia Faiz \\ Assistant Professor, Faculty of Management \& Social Sciences \\ Capital University of Science \& Technology Islamabad \\ shazia.faiz@cust.edu.pk \\ Um-e-Rubbab \\ Lecturer, Department of Business Administration \\ Fatima Jinnah Women University Rawalpindi \\ rubabsardar@gmail.com \\ Dr. Umar Nawaz Kayani \\ Assistant Professor, Faculty of Management \& Social Sciences \\ Capital University of Science \& Technology Islamabad \\ dr.umar.kayani@gmail.com
}

\begin{abstract}
Even though growing importance has been given to work-family conflict and deviant workplace behavior, the link between employees' feelings of work-family conflict and deviant workplace behavior is still missing. To explain this mechanism the study examines sequential mediation through stress and burnout.It'sa time lag study; data were collected through self- reported questionnaires. For a sample of 147nurses at government hospitals in Pakistan structural equation modeling was conducted.The results revealed strong support for the hypothesized relationships. The findings indicate work-family conflict indirectly but positively associated with deviant workplace behavior, sequentially mediated first through stress and then burnout.The study connects the dots, four main workplace attitudes as variables of action, reaction, outcome, and consequence, and figures out how this mechanism works and WFC leads to burnout.Limitations of the study along with the future research directions are also discussed.
\end{abstract}

Keywords: Work-family conflict, Deviant workplace behavior, Burnout, Stress

\section{1- Introduction}

Work-family conflict (WFC) is the outcome of the perceived incompatibility between work and family. The demands associated with jobs leave no margin for employees to 
contribute effectively in family affairs, ultimately leaving them with undesirable outcomes. Recent studies have already explored multiple organizational outcomes associated with WFC in the form of higher turnover intention (Syed et al, 2018;Anwar,Javed, Shaukat,2018; Wang, Lee \& Wu, 2017), lower satisfaction (Rhee, Park, \& Lee, 2020; Zain \&Setiawati,2019) and commitment(Akhtar \& Malik,2016) in multiple contexts like health (Zain \&Setiawati, 2019; Peng, Kuar, \& Cheng, 2016), education (Ahmad et al. 2020) banking (Garg, \&Yajurvedi, 2017), sales (Bande, Jaramillo, Fernández, \& Varela, 2019)hospitality(Pan \& The, 2019; Chen, Ayoun, \&Eyoun, 2018) and security by specifically targeting police(Qureshi, Lambert, \& Frank, 2019).

Few others focused on psychological outcomes associated with it in the form of perceived negativity, stress, distress (Houlfort, Philippe, Bourdeau, \& Leduc, 2018; Westrupp, 2016) depression (Grobelna, 2018) and workplace incivility (Abubakar, 2018). Still, there is a need to explore more outcomes and consequences associated with WFC at the individual and organizational level to deepen our insight.Thus, the current study explores its impact on deviant workplace behavior and broadensthe perspective of both organizational and psychological outcomes of WFC.

As perceived WFC divides employees' attention ultimately leaving them less focused and more involved in interpersonal deviance like gossips, blame game, and exploitation of basic norms (Swandarujati, Nurfitri, \&Anggraeni, 2020; Ju, 2018). More severe forms appear when employees show adverse behavior towards other coworkers like incivility, hostility, humiliation, harassment, and intimidation (Raja, Javed, \& Abbas, 2018; Thompson et. al. 2017).So, all these behaviors lead the organization towards losses. Another form of deviance is organizational deviance, effecting organizations directly in the form of loss of property, more absenteeism, and ultimately low productivity, and misuse of organizational resources (Tong, Bickmeier, \&Rogelberg, 2020). Consequently, leading the majority, intentionally and unintentionally to complete withdrawal physically, emotionally, and psychologically.

Recent studies call toidentifying the mechanism which leads this manageable form of conflict into severe and less manageable consequences. Thus, this study explores sequential mediatory mechanisms leading WFC to stress and stress to burnout and consequently leading to deviant workplace behavior. Swandarujati, Nurfitri, \&Anggraeni, (2020) gave a clue that the immediate outcome of WFC is stress. This, if not managed timely by both employees and organizations, leads employees towards burnout. Initially incompatible demands from both domains (work \& home) make routine bit challenging, leaving individuals with a feeling of overburdened. Additionally, this perceived negativity in the form of stress gives arousal to the feeling of burnout (Raja, Javed, \& Abbas, 2018) which is employees' perception of complete failure and exhaustion. Ultimately, encourage them to be reactive in the form of deviant workplace behavior.

Spillover theory supports our assumptions, as certain incidents, events, and ideologies have spillover effects, WFC is one of them, as this manageable conflict influences both 
domain workplace and home. Additionally, mismanagement of this initial incompatibility and contradictions lead to a series of negatives outcomes and consequences. Qureshi, Lambert, and Frank, (2019) also explained that the spillover phenomenon becomes hard to manage comparatively.

The present study contributes in many ways. Firstly, itadds theoretically by investigating sequential mediatory mechanisms firstly though stress and secondly through burnout to bring more clarity in this domain. Secondly, the study explores these observed patterns and associated behaviors in health sectors by targeting nurses of public hospitals only. As they have high vulnerability towards negativity due to complex and stressful job demands. Additionally, these concepts have wide recognition and acceptance in western society but limited studies showed serious concern in the Asian context, thus studying these life-changing perspectives technically in Pakistan generates valuable outcomes.

\section{2- Literature Review}

\subsection{Work-Family Conflict on Deviant Workplace Behavior}

Work-family conflict refers to inter role conflict, where role demands from one domain affect another domain adversely (Greenhaus\&Beutell 1985). Job demands typicallydrain employees, leave them completely exhausted, and with no space for family affairs, ultimately encouraging towards deviant workplace behavior (Thompson et al 2017). Deviant workplace behavior refers to voluntary behavior which severely violates organizational norms and consequently affects the well-being of both employees and organizations (Appelbaum, Laconi, \&Matousek, 2007). Mercado andDilchert, (2017)explored that the utmost obvious forms of deviant workplace behavior are interpersonal deviance and organizational deviance. Where former stimulate political deviance and personal aggression while later fortifiesthe negligent productivity behavior and property deviance (Tong, Bickmeier, \&Rogelberg, 2020).

Both forms bring serious concerns to organizations thus compelling management to take serious actions to manage effectively. Individuals facing WFC initially react in the form of interpersonal devianceby motivating themselves to show ingratiation, favoritism, gossips (Bande, Jaramillo, Fernández, \& Varela, 2019) thesepropensities give rise to an unhealthy environment. Later on,they become involved in more serious damaging behaviors like verbal abuse, harassment, and theft, etc. Raja, Javed, and Abbas (2018)gave a clue that WFC becomes more challenging when negativity heightens employees'inclination to take long breaks, show the least concern for discipline by increasing absences from duties. Additionally, using equipment and other resources carelessly. Some corrective measures, if not followed,the situation can be worsened in form of conspiracies, revengeful action, and so on.

Extent literature also shows that work-family conflict leads to negative outcomes, variability is quite high depending on the nature of organization and context(Qureshi, Lambert,\& Frank, 2019). It has been observed that if strict policies and practices followed by management than a mild form of organizational deviance experienced and 
vice versa. Zain and Setiawati (2019) also gave a hint that negative outcomes of WFC in the health sector are quite high. Specifically, if we focus on nurses it leads to more severe outcomes. Thus, based on this literature review we assume there

H1: Work-family conflict positively affects deviant workplace behavior. 2.2 Sequential Mediation of Stress and Burnout for the Relationship between WorkFamily Conflict and Deviant Workplace Behavior.

\subsubsection{Work-Family Conflict on stress}

Stress refers to an emotional reaction in the form of anger, tension, depression, and frustration (Mercado \&Dilchert, 2017). It seems normal apparently, but it can lead to a series of negative outcomes by affecting individuals' growth in both domains i.e., personal \& professional. Stress is manageable if it's acute; which appears in the reaction of minor problems, like fights, ignorance, and minor differences with others (Thompson et. al. 2017). Time heals everything and after some timeemployees feel less stressed. But the situation becomes critical when the felt stress is chronic; it's obvious in expressions of job dissatisfaction, and family problems. Individuals perceiving insufficient support from both mediums can lead to this intense form of stress. Swandarujati, Nurfitri, and Anggraeni (2020) have already concluded WFC as an obvious predictor of stressas incompatible job demands don't leave a margin for family responsibilities. By spending more exhausting time at work employees feel potentially devastated(Swandarujati, Nurfitri, \&Anggraeni, 2020).

Excessive work demands, lack of clarity in the task, and simultaneous assignment of tasks by higher authorities bring tension and anxiety among workers (Tong, Bickmeier, \&Rogelberg, 2020). Specifically, in the nursing context job complexity is comparatively high, the staff members feel stressed and expect some peace at family time. Things become worsen when family overstrains them to contribute to the family end as well but lack of energy and time makes it impossible to contribute enthusiastically (Ahmad et al. 2020). If this phase continues, in the long run, it leads employees towards stress. Grobelna (2018)also hinted that there exists a strong relationship between WFC and stress. Thus, we assume that:

\section{H2: WFC is positively related to stress}

\subsubsection{Stress on Burnout}

Stress leads to burnout because employees sometimes don't consider it a serious business, shortly it becomes the worst part of their lives (Peng, Kuar, \& Cheng, 2016). Burnout refers to the emotional loss in the form of emotional exhaustion, depression, and cynicism (Brummelhuis et al., 2011). Burn out appears in three obvious forms i.e., exhaustion, depression, and cynicism. Exhaustion decreases energy, ultimately leaving employees to perform their work ineffectively. Depression encourages individuals to maintain an emotional distance with others by showing annoying behavior, ultimately becoming disengaged from others in a circle.

Cynicism is an expression of showing unsympathetic attitudes toward others (Garg, \&Yajurvedi, 2017). Therecurrentmishandling and public expressions of anger, tension, 
and depression prove individuals nervous. Unhealthy remarks and criticism lead them to burn out. Specifically nurses every so often feel helpless and fully exhausted when they see it impossible to fulfill demands at both ends. Thejob prospects, constant pressure, and uncertainty worsen the things gradually and by degrees (Tong, Bickmeier, \&Rogelberg, 2020). Thus, burnout becomes obvious in the form of low self-worth, grief, and depression. Todd et al (2018) also gave a clue thatstress predicts burnout at the workplace. Consequently, employees show complete withdrawal from everything (Raja, Javed, \& Abbas, 2018). Thus, based on this literature review we assume that:

\section{H3: Stress is positively related to burnout}

\subsubsection{Burnout on Deviant Workplace Behavior}

The state of burnout gives birth to workplace deviance because employees use it as an escape mechanism. Emotionally abandoned and weary employees absorb themselves in relational and organizational deviance depending on the extent, rules allow them (Mulki et al., 2006). Mild interpersonal deviance observed in the form of criticism, harsh comments. But the existence of punishment mechanism restricts their involvement in severe property loss and damaged equipment. Houlfort, Philippe., Bourdeau, and Leduc, (2018) also gave a clue that excessive work demands in both domains and mismatch with individuals' capabilities lead them to more obvious negative outcomes.

Specifically, if we see nurses' excessive work demands and their passion to maintain balance in both domains i.e., at home and workplace simultaneously overburdens them, and then comes a series of negative spillovers. Thus, in agreement with recent studies, it is predicted that WFC isn't a single predictor of deviant workplace behavior. There is a proper mechanism that gradually thrusts employees to the state that they become comfortable / with misconduct, more precisely in the form of interpersonal and organizational deviance. It is assumed that the relationship between WFC and deviant workplace behavior is firstly mediated by stress, then by burnout.

H4: Burnout positively related to deviant workplace behavior

H5: Stress and Burnout act as sequential mediators between work-family conflict and workplace deviance

\section{WORK FAMILY}

CONFLICT

Figure 1: Conceptual model of the study 


\section{3- Research Methodology}

\subsection{Study context, Sample and Procedure}

For the study, data were collected from full-time working nursing stafffrom Rawalpindi Islamabad. So, there was a substantial scope for genuine feedback about the role of work-family conflict, stress, burnout, and deviant workplace behavior. The health sector in Pakistan specifically government hospitals, has already been identified as demanding with tough job requirements, thus, making it responsive to demands. Employees were surveyed by using a self-administered questionnaire.

To avoid the common method variance (CMV), especially associated with singlesource data, both procedural and statistical remedies were followed. Firstly, during data collection, respondents' anonymity was ensured, secondly,data were collected in time lags. The data about IV and med 1 was obtained in phase one. In phase two, after a gap of three weeks, data about med 2 and DV were obtained respectively. A total of 200 male and female nursing staffwas targeted for the study. They were required to fill selfreported questionnaires during each phase. Thus, 147 usable responses were obtained. Initial data analysis in SPSS 23 revealed that the majority of the respondents were females $64 \%$ and married $77 \%$ and $80 \%$ of the respondents fall in the age group of 31 to 41.

\subsection{Measures}

The measureswere adopted, respondents were required to mark responseson a 5point Likert scale for WFC, Stress, and Burnout with degrees that range from $1=$ strongly disagree, $5=$ strongly agree. While responses for workplace deviance were marked on a 7-point Likert scale. Work-family conflict was measured using the WorkFamily Conflict Test developed by Netemeyer et al (1996), which consists of 5 items. Job stress was measured by using the scale developed by the American Institute of Stress (2009), which contains 10 items. Burnout was measured using the Burnout Inventory(MBI-GS) developed by Schaufeli et al (1996), covers16 items. Lastly, the workplace Deviance Scale was measured by using the workplace deviance scale developed by Bennett \& Robinson (2000), with19 items.

\subsection{Results and Findings}

The scales were validated through reliability and validity. The reliability criteria were Cronbach's alpha coefficient and found satisfactory for each of the study variables. Amos 22 software was used, the convergent validity of the measurement items was assessed through confirmatory factor analysis (CFA). The results of measurement model (see table 1) indicated excellent fit statistics for the data of this study e.g., CMIN/DF 1.3, CFI (The Comparative Fit Index) $=0.907$, TLI (The Tucker Lewis Index) $=0.901$, IFI (The Relative Fit Index) .909 and RMSEA (The Root Mean Square Error of Approximation $)=0.04$. Thus, we moved for hypothesis testing. 
Table 1: Measurement model

\begin{tabular}{lccccc}
\hline Models & CMIN/DF & RMSEA & CFI & TLI & IFI \\
\hline 4factor Model & 1.31 & .04 & .907 & .901 & .909 \\
\hline
\end{tabular}

Table 1 shows the means, standard deviations, correlations, and reliabilities. Demographic variables of gender $(\mathrm{F}=.96, \mathrm{P}=.32)$ marital status $(\mathrm{F}=.84, \mathrm{P}=.43)$ and age $(\mathrm{F}=.46, \mathrm{P}=.49)$ found insignificantly correlated to variables under study in One Way Anova. Thus, were not controlled during the path analysis. The results of correlation analysis showed that WFC was significantly correlated with job stress $(r=.74, p<.05)$, with burnout $(\mathrm{r}=.62, \mathrm{p}<.05)$ and workplace deviance $(\mathrm{r}=14, \mathrm{p}>.05)$. Job stress was also significantly correlated with burnout $(\mathrm{r}=.68, \mathrm{p}<.05)$ and workplace deviance $(\mathrm{r}=.19$, $\mathrm{p}<.05)$. Burnout was also significantly correlated with workplace deviance $(r=.21, \mathrm{p}<.05)$. All variables show Cronbach's reliability above 0.70 .

Table 2: Means, Standard Deviations, Correlations and Reliabilities

\begin{tabular}{|c|c|c|c|c|c|c|c|c|c|}
\hline Variables & Means & S.D & 1 & 2 & 3 & 4 & 5 & 6 & 7 \\
\hline 1.Gender & 1.72 & 0.44 & -- & & & & & & \\
\hline 2.Age & 2.44 & 1.09 & - & & & & & & \\
\hline $\begin{array}{l}\text { 3.Marital } \\
\text { Status }\end{array}$ & & 0.27 & .18 & $.21 *$ & & & & & \\
\hline 4. WFC & 3.50 & 0.85 & .08 & -.06 & .00 & $(.76)$ & & & \\
\hline 5. Job stress & 3.73 & 0.83 & .05 & -.06 & -.07 & $.74 * *$ & (.89) & & \\
\hline 6. Burnout & 3.75 & 0.70 & .08 & -.09 & $.10^{* * *}$ & $.62 * *$ & $.68^{* *}$ & (.90) & \\
\hline & 3.64 & 0.53 & -.05 & -.13 & $.04 * *$ & .14 & $.19 *$ & .21 & (.83) \\
\hline
\end{tabular}

$* p<.05 ;$ Reliabilities are given in parenthesis

We estimated all of the hypothesized paths through the structural model and results revealed variance in outcome variables. Surprisingly, the findings provided no support for Hypothesis 1, the assumption that work-family conflict positively related to deviant workplace behavior $(\beta=0.14, p>0.01)$ has been rejected. But work-family conflict (WFC) appeared as a significant predictor of job stress $(\beta=0.74, p<0.01)$, supporting Hypothesis 2. Furthermore, job stress was found to be positively associated with burnout, also providing support for Hypothesis $3(\beta=0.68, \mathrm{p}<0.01)$. Lastly, burnout was observed as significantly related to deviant workplace behavior $(\beta=0.20, p$ $<0.01$ ), supporting hypothesis 4. 
Table 3:Path analysis for Direct effect and Mediation

From $\rightarrow$ To
WFC $\rightarrow$
$\mathrm{ST} \rightarrow$

\section{4- Discussion and Conclusion}

\subsection{Discussion}

The study findings make a significant contribution to the extant literature in several ways. The result showed rejection of our assumption that WFC is positively related to deviant workplace behavior. The findings revealed no significant relationship between the variables. It was a surprise, to unearth the reason doctors and nurses from family and friends circle were contacted. The discussion revealed that it's genuine and acceptable. Nursing no doubts is a noble profession but excessive work demands from both domains (professional and family) create inter role conflict for them. This common phenomenon leads to some serious negative outcomes but doesn't encourage them to involve immediately in deviant workplace behavior. Its time taking because nursing staff 
specifically female nurses don't allow themselves for immediate negativity. The study findings provide insight into Asian culture where nurses found more sympathetic, dedicated, and loyal with their professions. They try to manage things on their own wholeheartedly.

The results confirmed $\mathrm{H} 2$ and $\mathrm{H} 3$, WFC gives birth to stress. Result strengthen the findings of previous researchers (Abubakar, 2018; Westrupp et al 2016) that WFC is a common predictor of stress. Interference of work into family affairs has a spillover effect, more time at work leaves nursing staff with limited time for family, precisely for female nurses it is quite unacceptable in this society, consequently leaving them stressed. This situation leads to devastating outcomes when all efforts to maintain balance in both domains fail. Ultimately, they feel physically and emotionally shattered. In agreement with a recent study by Khamisa, Peltzer, Llic, \& Oldenburg (2017) the findings showed that emotional and psychological state becomes worsens over time. Excessive demands from work and family leave them helpless, they increase their effort, work like robots but the feeling of burnout leaves them anxious \& depress.

The findings also confirmed $\mathrm{H} 4$, that emotional exhaustion leaves a margin to manage things. The results are congruent with ShkolerandTziner (2017), where they found that burnout strengthens the probability of workplace deviance. Encourage nurses to be reactive; they release pressure by engaging themselves in deviant workplace behavior. Initially, they entertain themselves with gossiping, blaming others, verbally abusing others. Gradually their poor self-management and non-resilient behavior encourage them to deny responsibilities, take long breaks, enjoy by taking more leaves, act deceitfully, and cheat regarding work performance and so on.

The findings also supported our assumption in H5, that WFC doesn't solely predict deviant workplace behavior. There is a proper mechanism, specifically in the context of nurses, they face comparatively high work pressure and high family demands, leading them overstressed, consequently pushing them towards burnout and ultimately involving consciously and unconsciously in deviant workplace behavior. The findings are extensions of recent studies (Grobelna, 2018; Houlfort et al 2018; Pan \& Yeh 2019).

\subsection{Future directions and limitations}

The study was more concerned with identifying the explanatory mechanism leading WFC to deviant workplace behavior. Future research can explore more personal outcomes like well being, life satisfaction and perceived career success. The researchers have the margin to explore few other explanatory mechanism like slef efficacy. Additionally, future research can explore some buffering mechanisms like psychological hardiness or ethical leadership etc. The investigation to identify underlying moderating mechanisms can generate interesting findings. Furthermore, the study revealed findings by targeting the government sector only future studies can consider the private sector as well to assess variability in results. Additionally, in the research only nursing staff were targeted, other sectors and samples can expand our knowledge regarding psychological issues. 


\subsection{Practical implications}

The findings of the study guide specifically the health sector that common phenomenon can lead to detrimental outcomes, thus timely assessment can minimize the possibility of negative outcomes. Due respect, awareness, and acceptability regarding the nursing profession must be ensured. Additionally, the attention required for the provision of facilities such as child care, it can relax them to some extent. The more relaxed work schedule can also contribute positively. Likewise, the adequate staff at each hospital can help minimize work-family interference and ensure efficacy and effectiveness by staff members. Training programs related to stress management and emotional intelligence can also help to minimize the stream of issues.

\subsection{Conclusion}

The health sector is the backbone of the country but unfortunately is under immense pressure in the $21^{\text {st }}$ century. The study helped in assessing problems faced by nursing staff in their routine life. The findings provided deep insight and opened new avenues for understanding and discussion. Nursing staff more specifically male nursing staff protested about the societal double standards regarding the acceptability of their job. As it's a taboo that it's not good for males, but lack of job opportunities instigates them to continue and survive. While females indicated job acceptance but grumbled limited support from their partners and family.

They stressed that the job is being considered their discretionary choice, so high demands for family affairs remain the same, ultimately overburdens them. But their passion for job and family instigate them to show exceptional performance in both domains leaving them with inter role conflict. As the balance is too difficult and mismanagement motivates them to deviant workplace behavior gradually. Initially, they feel incompetent and guilty for poor managing but progressively they ease their guilt and incompetence by involving in interpersonal deviance. Lack of support from both domains strengthens their tendencies towards organizational deviance later on. Now we are clear that in developing countries, especially in Asian counties WFC has spillover effects, it has several psychological outcomes effecting on individual and organization level. Thus, steps must be taken to manage WFC at initial stages to avoid devastating outcomes and consequences.

\section{Disclosure statement}

No potential conflict of interest was reported by the authors.

\section{References}

Abubakar, A. M. (2018). Linking work-family interference, workplace incivility,gender, and psychological distress. Journal of Management Development.

Ahmad, M., Muazzam, A., Anjum, A., Visvizi, A., \& Nawaz, R. (2020). Linking Work- 
Family Conflict (WFC) and Talent Management: Insights from a Developing Country. Sustainability, 12(7), 2861.

Akhtar, S., \& Malik, M. F. (2016). Effect of Boredom and Flexible Work Practices on the Relationship of WFC with Procrastination and Affective Commitment: Mediation of Non-Work-Related Presenteeism. Global Journal of Flexible Systems Management, 17(4), 343-356.

Anwar, F., Javed, A., \& Shaukat, M. Z. (2018). Antecedents of work exhaustion, its mediating role and subsequent effects on turnover intentions. Management, 16, 18

Appelbaum, S. H., Iaconi, G. D., \&Matousek, A. (2007). Positive and negative deviant workplace behaviors: causes, impacts, and solutions. Corporate Governance: The international journal of business in society.

Bande, B., Jaramillo, F., Fernández-Ferrín, P., \& Varela, J. A. (2019). Salesperson coping withwork-family conflict: The joint effects of ingratiation and self-promotion. Journal of Business Research, 95, 143-155.

Bowen, P., Govender, R., Edwards, P., \& Cattell, K. (2018). Work-related contact, workfamilyconflict, psychological distress and sleep problems experienced by construction professionals: an integrated explanatory model. Construction Management and Economics, 36(3), 153-174.

Chen, H., Ayoun, B., \&Eyoun, K. (2018). Work-Family Conflict and turnover intentions: A study comparing China and US hotel employees. Journal of Human Resources in Hospitality \& Tourism, 17(2), 247-269.

Garg, P., \&Yajurvedi, N. (2017). Assessing the Impact of Stress on the Work-Life of Bank Employees-A Case Study of Meerut Region. Siddhant-A Journal of Decision Making, 17(1), 1-8.

Grobelna, A. (2018). What is WrongWith The Quality of Hotel Service? The Critical Role ofWork-Family Conflict and Its Negative Outcomes. International Journal of Contemporary Management, 17(3), 125-151.

Hayes, A. F. (2009). Beyond Baron and Kenny: Statistical mediation analysis in the new millennium. Communication Monographs, 76(4), 408-420. 
Houlfort, N., Philippe, F. L., Bourdeau, S., \& Leduc, C. (2018). A comprehensive understanding of the relationships between passion for work and work-family conflict and the consequences for psychological distress. International Journal of Stress Management, 25(4), 313.

Ju, H. (2018). Work-To-Family Conflict and Workplace Deviance: A Self-Regulatory

Perspective. In Academy of Management Proceedings (Vol. 2018, No. 1, p. 13225). Briarcliff Manor, NY 10510: Academy of Management.

Khamisa, N., Peltzer, K., Ilic, D., \& Oldenburg, B. (2017). Effect of personal and work stress onburnout, job satisfaction, and general health of hospital nurses in South Africa. health sagesondheid, 22(1), 252-258.

Koopman, J., Rosen, C. C., Gabriel, A. S., Puranik, H., Johnson, R. E., \& Ferris, D. L.

(2019). Why and for whom does the pressure to help hurt others? Affective and cognitive mechanisms linking helping pressure to workplace deviance. Personnel Psychology.

Lee-Peng, N., Kuar, L. S., \& Cheng, W. H. (2016). Influence of work-family conflict and work-family positive spillover on healthcare professionals' job satisfaction. Business Management Dynamics, 5(11), 1.

Mercado, B. K., \&Dilchert, S. (2017). Family interference with work and its relationship with organizational citizenship and counterproductive work behaviors. International Journal of Selection and Assessment, 25(4), 406-415.

Pan, S. Y., \& Yeh, Y. J. (2019). The crossover effect of work-family conflict among hotel employees. International Journal of Contemporary Hospitality Management.

Qureshi, H., Lambert, E. G., \& Frank, J. (2019). When Domains Spill Over The

Relationshipsof Work-Family Conflict With Indian Police Affective and Continuance Commitment. International journal of offender therapy and comparativecriminology, 63(14), 2501-2525.

Raja, U., Javed, Y., \& Abbas, M. (2018). A time-lagged study of burnout as a mediator in 
the relationship between workplace bullying and work-family conflict. International journal of stress management, 25(4), 377.

Rhee, M. K., Park, S. K., \& Lee, C. K. (2020). Pathways from workplace flexibility to turnover intention: Role of work-family conflict, family-work conflict, and job satisfaction. International Journal of Social Welfare, 29(1), 51-61.

Robinson, S.L. and Bennett, R.J. (1995), “A typology of deviant workplace behaviors: a multidimensional scaling study", Academy of Management Journal, Vol. 3. 2, pp. 555- 72 .

Shkoler, O., \&Tziner, A. (2017). The mediating and moderating role of burnout and emotional intelligence in the relationship between organizational justice and work misbehavior. Revista de Psicología del Trabajo y de las Organizaciones, 33(2), 157-164.

Swandarujati, m., Nurfitri, t., \&Anggraeni, a. I. (2020). Effect of organizational justice on stress with work-family conflict as a mediating variable. Journal of research in management, 2(4).

Syed, A., Ahmad, M. B., Ali, H. F., Arif, M. M., \& Gohar, A. (2018). Work-Family Conflict andTurnover Intentions: Moderated Mediation Model. Human Resource Research, 2(1), 95-106.

Thompson, M., Carlson, D. S., Butts, M., \& Weaver, S. (2017). The Cost Of Work's Tense TriadOn Employee Healthcare Utilization. In Academy of Management Proceedings (Vol. 2017, No. 1, p. 11581). Briarcliff Manor, NY 10510: Academy of Management.

Tong, J., Bickmeier, R. M., \&Rogelberg, S. G. (2020). A Comparison of Frequency-and

Agreement-Based Response Formats in the Measurement of Burnout and Engagement. International Journal of Environmental Research and Public Health, 17(2), 543.

Wang, I. A., Lee, B. W., \& Wu, S. T. (2017). The relationships among work-family conflict, turnover intention and organizational citizenship behavior in the hospitality industry of Taiwan. International Journal of Manpower. 
Westrupp, E. M., Strazdins, L., Martin, A., Cooklin, A., Zubrick, S. R., \& Nicholson, J. M. (2016). Maternal work-family conflict and psychological distress: reciprocal relationships over 8 years. Journal of Marriage and Family, 78(1), 107-126.

Zain, A. N. D., \&Setiawati, T. (2019). Influence of Work-Family Conflict and Job Satisfactionon Medical Employee Performance through Organizational Commitment. Review of Integrative Business and Economics Research, 8(1), 119.

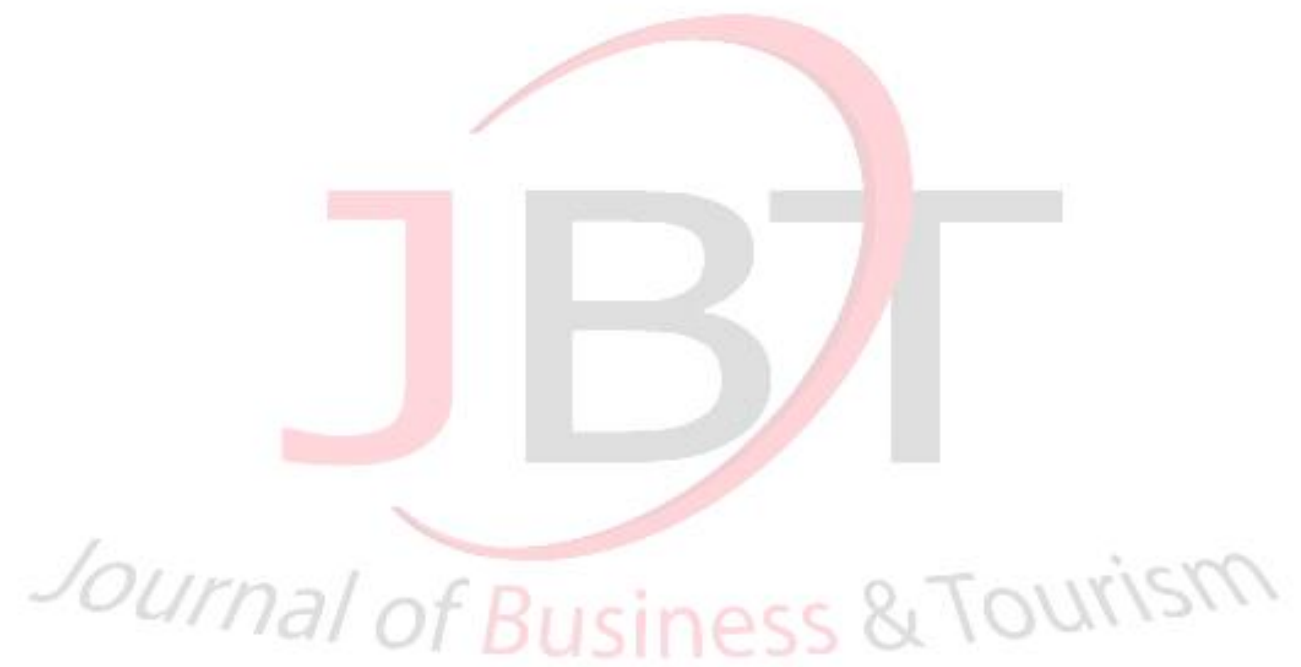

